\title{
Las mujeres como objeto sexual y arma de guerra en espacios de conflicto armado de México y Colombia y el papel de los medios de comunicación
}

\author{
Javier JUÁREZ RODRÍGUEZ \\ Universidad Complutense de Madrid \\ Juarezprensa@yahoo.es
}

Recibido: 19 de agosto de 2014

Aceptado: 17 de septiembre de 2014

\section{Resumen}

El presente trabajo es resultado de seis años de documentación y la realización de cientos de entrevistas a personas vinculadas con casos de violencia contra niñas y mujeres en espacios de conflicto armado en México y Colombia. El documento analiza la situación de discriminación y violencia sistemática que sufren niñas y mujeres en este contexto, centrándolo en espacios que ejemplifican la impunidad y permisividad del sistema patriarcal. Además, se analiza el importante papel de medios y periodistas en estos espacios y las dificultades que conlleva investigar y denunciar esta realidad.

Palabras clave: Feminicidio; Guerra; Secuestros; Explotación sexual; Drogas; Periodistas.

\section{Women as sexual objects and as weapon in armed conflict areas of México and Colombia and the role of media}

\begin{abstract}
The present article is the result of six years of documenting and interviewing hundreds of people involved in cases of violence against women in areas of armed conflict in México and Colombia. This document analyzes the systematic discrimination and violence directed towards girls and women living in these areas by focusing on settings that exemplify the impunity and permissiveness of the patriarchal system. In addition, the present work not only details the important role played by journalists and the media, but it also highlights the obstacles that they must overcome while attempting to investigate and expose this reality.
\end{abstract}

Key words: Femicide; War; Kidnapping; Sexual Exploitation; Drugs; Journalists.

\section{Referencia normalizada:}

Juárez Rodríguez, J. (2014) Las mujeres como objeto sexual y arma de guerra en espacios de conflicto armado de México y Colombia y el papel de los medios de comunicación. Historia y Comunicación Social. Vol. 19. Páginas 249-268.

Sumario: 1. Introducción. 2. Metodología. 3. México: paraíso de la impunidad ante los feminicidios y la trata con fines de explotación sexual de niñas y mujeres. 4. Colombia: conflicto armado y crímenes de Estado. 5. Conclusiones. 6. Referencias bibliográficas. 


\section{Introducción}

Este artículo pretende analizar un aspecto invisibilizado en los últimos años como es la impunidad que rodea a los casos de violencia extrema, agresiones, secuestros y asesinatos sistemáticos de mujeres en espacios de conflicto armado o dominados por estructuras ligadas al crimen organizado. El análisis realizado centra su campo de estudio en dos zonas especialmente golpeadas por estos fenómenos como son México y Colombia, y consta de testimonios inéditos que reflejan la citada impunidad que rodea a estos casos, que, como veremos, vienen precintados por un total hermetismo institucional que hace muy compleja su documentación y, consecuentemente, dificulta en gran medida su posible denuncia como paso previo a la visibilización social y posterior combate y erradicación.

Las mujeres como botín de guerra en espacios en disputa por estructuras delictivas o su utilización como objetos sexuales ritualísticos entre los miembros de estructuras del crimen organizado son realidades que azotan día a día a miles de mujeres en Latinoamérica ante la actitud cómplice e indolente de unas Autoridades permisivas que protegen, potencian y garantizan la impunidad por el mero hecho de ser mujeres y ser pobres, condiciones que fomentan y "justifican" la normalización social de esta realidad dentro de unas estructuras políticas y culturales patriarcales y misóginas.

\section{Metodología}

Para la elaboración de este artículo científico hemos recurrido a distintas estrategias y métodos de investigación acordes al carácter complejo de nuestro ámbito de trabajo que ha hecho necesario compaginar métodos cualitativos y cuantitativos. La perspectiva cualitativa ha ayudado a comprender el fenómeno de estudio en su ambiente y contexto, desplazándonos a México y Colombia con el objetivo de observar cómo se desarrollan los elementos objeto de estudio, interactuando con las personas y agentes que intervienen en el fenómeno estudiado: autoridades del ámbito local, estatal y regional; periodistas, activistas y madres y padres de las propias familias afectadas.

Del mismo modo, en el análisis y el estudio del contexto hemos abordado la importancia del impacto y papel social de los medios a la hora de interpretar, o no, esta realidad. Paralelamente para el desarrollo del trabajo ha sido necesaria la búsqueda de fuentes de primera mano en un contexto extremadamente complejo y peligroso. De hecho, durante la elaboración del presente artículo dos de las fuentes consultadas han sido asesinadas (el periodista Armando Rodríguez y la activista Marisela Escobedo) y otras han tenido que abandonar estos espacios tras recibir amenazas de muerte. En este clima de violencia extrema y acoso, amparado por una impunidad latente, se hacen más valiosos si cabe los testimonios conseguidos. También hemos empleado un enfoque cuantitativo para analizar argumentaciones, fundamentalmente de las fuentes oficiales, de las propias Autoridades, a la hora de constatar y argumen- 
tar con cifras y datos supuestos avances y mejoras en lo referente a las políticas para combatir la violencia contra las mujeres en México y Colombia.

\section{México: Paraíso de la impunidad ante los feminicidios y la trata con fines de explotación sexual de niñas y mujeres}

Hilda Gabriela Rivas Campos salió de su casa la mañana del 25 de febrero de 2008 rumbo al centro de Ciudad Juárez para buscar trabajo. Fue vista en algunos comercios cercanos a la Catedral donde entregó solicitudes de empleo. Sería la última vez que la joven, de sólo 16 años, sería vista con vida. Sus restos fueron entregados a sus padres tres años más tarde, aunque el cuerpo de Hilda Gabriela fue localizado apenas unos días después de reportar su desaparición. "Su cuerpo estaba tirado junto a un arroyo, en el Valle, a unos 60 kilómetros de la Ciudad Juárez" (Juárez, 2012; p127.) en una zona militarizada, muy peligrosa y dominada por el crimen organizado. Las Autoridades no sólo no investigaron, sino que ocultaron de forma premeditada el cuerpo de la joven durante más de tres años ${ }^{1}$ con la consiguiente pérdida de pruebas e imposibilitando avances para la localización de sus asesinos. La Fiscalía entregó a sus padres en abril de 2011 "unos cuantos huesos y un trozo de mandíbula" sin aportar más datos o explicaciones. (El Diario de Ciudad Juárez, 14-04-2011). El caso de Hilda Gabriela ejemplifica el grado de impunidad que impera, aún hoy, en el Estado de Chihuahua en particular, y en toda la República mexicana en general, en relación a los casos de secuestros, violaciones y asesinatos sistemáticos de mujeres enmarcados dentro de un sistema que permite y potencia esta impunidad como garante de "una cultura de la violencia y la discriminación" (Giletti 2014: p5.) hacia las mujeres.

El sexenio de Felipe Calderón (2007/2013) (PAN) se cerró con más de 12.000 mujeres asesinadas ${ }^{2}$, disparando las tasas de feminicidios hasta cotas nunca antes documentadas y multiplicando los casos de desapariciones forzosas de mujeres y adolescentes. Esta agudización de los casos de violencia extrema contra las mujeres en México debemos contextualizarlo, además, dentro de una realidad política y social enmarcada en la proliferación de estructuras delictivas ligadas a la trata de personas, el tráfico de drogas y de armas.

La multiplicación de las células del crimen organizado se instalará en los principales Estados y ciudades para conseguir el control de las plazas en disputa e infiltrarán sus tentáculos en todos los estamentos y a todos los niveles para conseguir sus objetivos. Este estallido de violencia supondrá el desembarco de verdaderos ejércitos de sicarios y la consolidación de zonas de guerra donde, como veremos, mujeres y niñas se han convertido en "botín de guerra de un país donde prevalece el machismo" y en el que "aumenta la esclavitud, la prostitución o las violaciones"3.

El llamado "Operativo Conjunto" impulsado por el Gobierno panista de Felipe Calderón para "combatir" el narcotráfico, jamás vino respaldado por una estrategia de protección a las mujeres y las niñas, sino que fundamentó sus acciones en una 
campaña de militarización de las principales ciudades y municipios en disputa por las estructuras del crimen organizado, careciendo de una estrategia integral que hiciera frente a las aristas que convergen en este fenómeno. Seis años después, el balance de las políticas impulsadas por el gobierno conservador no pudo ser más desolador, dejando en evidencia, además, la corrupción imperante dentro de las fuerzas militares y policiales desplegadas por toda la República, en muchos casos vinculadas con las citadas estructuras criminales. Aunque, una vez más, resulta muy complejo cifrar de forma exacta el número de personas asesinadas como consecuencia de esta "guerra fratricida", se estima que durante el sexenio de Felipe Calderón fueron asesinadas entre 60.000 y 90.000 personas, a las que hay que sumar más de 21.000 hombres y mujeres reportados desaparecidos ${ }^{4}$ y las más de 5.500 denuncias documentadas contra militares y federales por abusos, secuestros o violaciones.

Es en este contexto de inseguridad e impunidad donde debemos situar los casos de violencia contra las mujeres documentados en espacios dominados por el crimen organizado, zonas en disputa por los brazos armados de los cárteles y en los que, además, se dio la inclusión de unas fuerzas policiales y militares corruptas. Espacios como Ciudad Juárez (Chihuahua) o Apodaca (Nuevo León) son muestra clara y reflejo del fracaso de una sociedad patriarcal y misógina basada en una cadena estructural que protege, permite y potencia la continuidad del propio sistema y la pervivencia de la impunidad sobre los casos de violencia contra las mujeres.

Nos situamos ante una estructura social, política, judicial y policial que sustenta el patriarcado que, a su vez, valida la misoginia y la violencia sexual contra las mujeres "y su expresión máxima es el asesinato de la mujer, con el cual se produce una estrategia de mantenimiento del control patriarcal a costa de la vida de las mujeres (...) la violencia contra las mujeres es producto de pactos patriarcales" (Ravelo 2006: p2.) Las propias estructuras sociales y gubernamentales serán garantes de que perdure esta impunidad y, consecuentemente, este sistema que "legitima y convalida la violencia" (Femenías 2010: p61.) contra las mujeres fomentando las políticas machistas "consistentes en la discriminación basada en la creencia de que los hombres son superiores a las mujeres". Todo ello validará la consolidación del sexismo como garante de la impunidad, entendido como "el conjunto de todos y cada uno de los métodos empleados en el seno del patriarcado para poder mantener en situación de inferioridad, subordinación y explotación al sexo dominado: el femenino" (Varela 2005: p180.)

La llamada "violencia del narco" ha silenciado totalmente una realidad que esconde feminicidios, negligencias, secuestros sistemáticos, complicidades, trata de menores... toda una cadena de casos y ejemplos de violencia contra las mujeres que ha logrado asentarse con total impunidad. Esta "consolidación" de un Estado paralelo, conformado por estructuras de crimen organizado, más fuerte aún que el propio Estado legítimo ha logrado, además, "normalizar" esta violencia contra las mujeres, la impunidad y un Estado patriarcal extremo donde niñas y mujeres son sólo objetos sexuales y/o fuentes de ingreso de dinero dentro de un sistema corrupto con toda una base que permite su expansión a nivel internacional. 
Los llamados "focos rojos" de la guerra contra el narcotráfico han sido y son espacios de alto riesgo para niñas y mujeres que no cuentan con respaldo y/o apoyo alguno desde los diferentes Gobiernos; al contrario, Autoridades y Estado son, salvo contadas excepciones, parte principal del problema junto a la campaña de desinformación existente en relación a estos casos. En este sentido, hemos de denunciar que, haciendo un trabajo de documentación y análisis científico vemos como, pese a la gravedad de los hechos y la multiplicación de los casos de secuestros y feminicidios sistemáticos de niñas y mujeres en las zonas mencionadas, los diferentes estamentos Gubernamentales jamás han afrontado esta realidad desde una óptima comprometida para tratar de poner luz en los casos; al contrario, a la ausencia de un Plan Federal Integral para su erradicación se suma, además, un indignante desinterés que impera en todos los niveles de todas las administraciones. Los secuestros y asesinatos sistemáticos de mujeres y niñas entre 2008 y 2013 en zonas como Ciudad Juárez (Chihuahua) o Apodaca (Nuevo León) o más recientemente en zonas humildes del Estado de México como Ecatepec y las respuestas dadas por las Autoridades constituyen un delito de Estado, con unos Gobierno permisivos y negligentes que permiten y amparan la impunidad.

Como exponíamos anteriormente, el estallido de violencia consumado en México, especialmente a partir de 2008, generó focos de extrema peligrosidad en el país debido al desembarco progresivo de "narcoejércitos" desplegados para conseguir el control de plazas estratégicas. El "Operativo Conjunto Chihuahua" supuso la llegada al Estado, básicamente en Juárez y su entorno, de más de 9.000 efectivos militares y policiales y el punto de partida de secuestros y asesinatos sistemáticos de niñas y mujeres. Este operativo conllevó la "militarización" de la ciudad mediante la instalación de "retenes en las calles de Ciudad Juárez en búsqueda de personas armadas" llevando a cabo "la instalación sorpresiva de los denominados puestos de control móviles" y ejecutando "cateos en viviendas" (El Diario de Ciudad Juárez, 23-012008) Este despliegue militar y policial vino acompañado por el repunte de la violencia en n Ciudad Juárez en un 2008 que "fue una pesadilla. En esos 12 meses hubo 1.653 ejecuciones (...) que representan cerca de una tercera parte del total nacional" (Chávez 2009: p117.)

A partir de entonces, tanto José Reyes (2004 - 2010) como de César Duarte, Gobernadores del Estado, han mantenido una estrategia común a la hora de afrontar los mencionados casos de violencia extrema contra mujeres y niñas basada en: hermetismo, confusión, minimización de los hechos y culpabilización de las propias víctimas; tácticas que, lamentablemente, son y han sido una constante en los diferentes gobiernos estatales donde PRI y PAN se han alternado y mantenido desde hace ya más de 20 años. Entre 2008 y 2014 (seis años) serán asesinadas en Ciudad Juárez más de 800 mujeres, es decir, casi el doble que en el período comprendido entre 1993 y 2007 (quince años), fechas en las que la ciudad fue señalada internacionalmente por los feminicidios sexuales documentados e institucionalizados por el propio Gobierno.

Desde entonces, "los crímenes sexuales ocurridos en Ciudad Juárez son una manifestación de la cultura de la violencia legitimada" (Limas 2002: p48.) por el propio 
Gobierno, garante de la impunidad y el continuismo de los mismos. A partir de 2008, mujeres y niñas estarán en el punto de mira de estas estructuras delictivas que, muy probablemente, contaron con el apoyo y/o complicidad de miembros del propio ejército y las fuerzas policiales. En este período, cada 20 horas una mujer será asesinada en el Estado de Chihuahua ${ }^{5}$ y una adolescente será secuestrada cada dos semanas, documentándose en momentos de intensa violencia "una desaparición cada día en el centro" (Norte de Ciudad Juárez, 24-07-11) todo ello ante la más humillante pasividad de las Autoridades de la Fiscalía de Ciudad Juárez.

Hablamos de un entorno extremadamente hostil que dispone, además, de espacios dominados por estructuras delictivas que, a su vez, cuentan con la impunidad como garante de sus acciones. La Zona Centro de Juárez y el Valle han sido dos de estos espacios y focos permanentes de los secuestros sistemáticos de adolescentes y desembarco de estructuras delictivas desde 2008 hasta la fecha.

Los feminicidios documentados desde el inicio del Operativo Conjunto han situado al Estado de Chihuahua a la cabeza de los espacios con mayores índices de asesinatos de mujeres. El visitador de la Comisión Estatal de Derechos Humanos (CEDH) de Chihuahua, Gustavo de la Rosa, denunciará públicamente que entre 2008 y 2014 se multiplicarán las denuncias de "víctimas de los abusos de los cuerpos policíacos y militares" además de casos de "violaciones sexuales tumultuarias contra mujeres perpetradas por hombres armados" y "abusos que han sufrido las mujeres como resultado de los operativos", afirmaciones recogidas en el trabajo "Información para el pacto de derechos políticos y sociales sobre feminicidio y desapariciones en Ciudad Juárez y Chihuahua y sobre violaciones a derechos humanos de las mujeres en el contexto de militarización y narco-violencia" elaborado por las organizaciones Justicia para Nuestras Hijas y Centro de Derechos Humanos de las Mujeres AC. En el citado informe se destaca además que estos hechos han sucedido y suceden en un Estado, Chihuahua, que es "la entidad federativa de México con mayores recomendaciones por instancias nacionales e internacionales por la violación de derechos humanos en contra de las niñas y mujeres". Estos datos reflejan el fracaso de una sociedad y la ineptitud de una Autoridad regida por principios machistas que perpetúan las reglas de una sistema patriarcal agudo en el que, sistemáticamente, se ha justificado la violencia contra las mujeres.

Si grave ha sido la actitud del Gobierno ante los feminicidios documentados en Ciudad Juárez entre 2008 y 2014 más grave aún ha sido su labor a la hora de afrontar los casos se secuestros sistemáticos de adolescentes, y es que "mientras el combate del narcotráfico ha acaparado enormes recursos públicos, con las mujeres no sucede lo mismo (...) no ocupa el mismo rango en la jerarquía de las preocupaciones oficiales" (Padilla 2002; p223.)

Las desapariciones sistemáticas de adolescentes han venido acompañadas por una desconcertante pasividad de las diferentes Administraciones, que jamás han priorizado en la búsqueda de estas niñas y mujeres, muchas de ellas menores de edad. Es más, en muchos de los expedientes documentados observamos que ni tan siquiera se 
activaron lo protocolos de actuación existentes para la búsqueda de desaparecidas de alto riesgo, incumpliendo las recomendaciones previas para abordar con efectividad estos casos. El aspecto que evidenció la red de mentiras y complicidades Estatales entorno a esta realidad fue la denuncia pública de ocultación "en la morgue" de Juárez de cuerpos de jóvenes reportadas desaparecidas. Las Autoridades no sólo no buscaron nunca a las jóvenes, sino que, de forma premeditada, hacinaron sus cuerpos durante años, impidiendo cualquier investigación y ocultando a la opinión pública la realidad: que las jóvenes reportadas desaparecidas desde 2008 hasta la fecha no eran, como argumentaron, adolescentes que habían abandonado sus hogares por su propia voluntad, sino que habían sido víctimas de una o varias estructuras feminicidas que actuaban, y muy probablemente siguen actuando, en Juárez, con total impunidad.

El Gobierno fue consciente de la gravedad de los hechos "y quiso mantenerlo en secreto (...) y que no se hiciera un escándalo de grandes magnitudes" (Norte de Ciudad Juárez, 26-02-1012) Entre abril de 2011 y mayo de 2014 las Autoridades entregaron más de 40 cuerpos de jóvenes reportadas desaparecidas (el último el de Mónica Janeth Alanís, secuestrada en marzo de 2009 y cuyos restos fueron entregados a sus padres en enero de 2014 "después de casi cinco años de abandono oficial"7) gracias a la presión de las propias familias, activistas y las denuncias de algunos medios y periodistas. En abril de 2012, los medios denunciarán la localización "en un mismo punto del Valle de Juárez" de "restos de 12 mujeres, 5 de ellas menores" advirtiendo que "es probable que la cifra de víctimas aumente hasta 14" (El Diario de Ciudad Juárez, 17-04-2012). Muchas de ellas fueron localizadas en fosas comunes situadas en espacios desérticos y alejados cuyos accesos sólo eran viables previo paso por retenes militares situados en la carretera Juárez-El Porvenir, transitando, además, municipios controlados por el crimen organizados y las fuerzas policiales y militares desplegadas en Juárez y su Valle.

Hablamos pues de un feminicidio sistemático de adolescentes, en zonas dominadas por el crimen organizado, silenciado por la propia Autoridad gracias, en parte, a la campaña de desinformación admitida por algunos medios del Estado, que jamás han dado a estos hechos la dimensión y gravedad que merecen. Sólo la persistencia de las familias de las desaparecidas y/o asesinadas - esencialmente las madres de las jóvenes, construyendo un movimiento de sororidad, entendido como "una solidaridad específica, la que se da entre las mujeres que por encima de sus diferencias y antagonismos se deciden por desterrar la misoginia y sumar esfuerzos, voluntades y capacidades, y pactan asociarse para potenciar su poderío y eliminar el patriarcalismo de sus vidas y del mundo" (Lagarde 2012: p34.) - han conseguido girar el foco mediático y, al mismo tiempo, lograr pequeños avances como, por ejemplo, la puesta en marcha en 2012 de una Fiscalía especializada en atención de mujeres víctimas del delito por razones de género.

Pese a todo, la impunidad sigue manteniéndose y las estrategias gubernamentales para minimizar la realidad y culpabilizar a las víctimas siguen adelante. Hemos de señalar que una táctica común en estos años ha sido culpabilizar a las víctimas; en unos casos alegando que las jóvenes secuestradas o asesinadas eran prostitutas (algo 
que en una mente retorcida y misógina debe dar cabida y legitimar al asesinato de las mujeres) y más recientemente vinculando a las jóvenes con el crimen organizado sin prueba alguna. Si una joven era violada, secuestrada o asesinada inmediatamente y sin investigación previa, las Autoridades acuñaban la posibilidad de que tuvieran nexos con el crimen organizado, justificando de este modo lo sucedido. Es toda una cadena impermeable a las críticas para justificar su indolencia y su pasividad, una cadena que, además, actúa de forma hostil contra quienes visualizan la misma. Entre 2008 y 2014 numerosas madres y activistas han sido amenazas de muerte (entre ellas Carla Castañeda, Marisela Ortiz, Norma Esther Andrade o Francisca Galván) y se han visto obligadas a abandonar la ciudad; otras han sido asesinadas, como a Josefina Reyes en enero de 2010; Marisela Escobedo, ejecutada en diciembre de 2010 de un disparo a la cabeza frente al Palacio Presidencial de Chihuahua durante el transcurso de una protesta para exigir la detención del asesino de su hija; Josefina Reyes Salazar, activista asesinada tras denunciar abusos y corrupción de las fuerzas militares desplegadas en el Valle de Juárez; o Susana Chávez, asesinada en enero de 2011.

Al igual que Ciudad Juárez, numerosos espacios se han consolidado en los últimos años como focos de impunidad entorno a los casos de violencia extrema contra niñas y mujeres en México; espacios, como la ciudad fronteriza, en disputa por estructuras del crimen organizado, que han impuesto un sistema de terror para acallar cientos de secuestros sistemáticos de adolescentes. Nos enfrentamos, en gran parte de estos casos, a estructuras organizadas relacionadas con la trata de mujeres con fines de explotación sexual que cuentan con un sistema de redes y complicidades que permiten su implantación en zonas en conflicto.

Los Estados de Tamaulipas y Nuevo León se han convertido entre 2009 y 2014 en focos de actuación de estas estructuras delictivas, aprovechando en parte la violencia extrema desatada como consecuencia de los enfrentamientos entre los ejércitos de $\mathrm{El}$ Cártel del Gofo y Los Zetas. A la ineficacia de las fuerzas de seguridad del Estado se suma la multiplicación de los capítulos de homicidios y extorsiones, que facilitaron más si cabe la extensión y normalización de la "captación" y secuestro de cientos de niñas y mujeres en las zonas mencionadas. La Trata de Mujeres - entendida como "la práctica que implica el traslado de personas dentro y fuera de su propio país para explotarlas sexualmente. Puede ser el resultado del uso y abuso de la fuerza, la coerción, manipulación, engaño, abuso de autoridad, presiones familiares, violencia familiar y comunitaria, privación económica y otras condiciones de desigualdad de mujeres" (López 2010: p5.) - se ha conformado, en palabras de Yolanda Besteiro, Presidenta de la Federación de Mujeres Progresistas, en entrevista realizada en enero de 2014 para este trabajo, en "la nueva forma de esclavitud del siglo XXI", y México se ha consolidado, por diversos factores, como foco de implantación y proliferación de estas estructuras.

Afrontar una investigación periodística y una documentación rigurosa de estos casos resulta una labor costosa y peligrosa. Como afirma el periodista mexicano Eduardo Cano, en entrevista realizada en 2011 en Ciudad México durante el transcurso de esta investigación, "cuando te enfrentas a ello eres consciente de la impu- 
nidad que hay, de lo fácil que resulta llevarte (en México) a una chica, y de que la autoridad en muchos casos ni actúe (...) son jovencitas que una vez enganchadas sufren encierros, amenazas, violaciones tumultuarias. Las destruyen (...) es un drama tremendo que no sólo ocurre en Juárez (...) los delincuentes tienen allí su negocio. Cuando esos grupos criminales se enfrentan por la plaza ocurre una explosión de violencia y ellos ven negocio en esta situación de caos (...) reclutan a jovencitas y hacen negocio con ellas y una vez que las toman ya no las sacas de allí (...) cuentan con amparo de la autoridad, tienen estructura, las venden, las golpean, las violan (...) todo es negocio" (Juárez 2012: pp. 93-94.)

Tras muchas de las desapariciones de mujeres en los Estados de Nuevo León y Tamaulipas documentadas entre 2009 y 2014 podemos visibilizar el complejo entramado que sostiene a estas redes y la vinculación directa, incluso, de las propias Autoridades, más preocupadas, como sucediera en Ciudad Juárez, por minimizar los hechos y las cifras que por localizar a las jóvenes secuestradas. Estas estructuras, además, suelen operar durante un tiempo, hasta que medios y familias visualizan la problemática, momento en el que suelen abandonar la plaza para ubicarse en nuevos municipios donde, de una vez más, "captan" o secuestran a nuevas víctimas.

El Gobierno de Felipe Calderón intentó, sin éxito, unificar los esfuerzos a nivel Federal para luchar contra la Trata de Mujeres con la puesta en macha de la Ley para Prevenir y Sancionar la trata de personas cuyo reglamento se puso en marcha en febrero de 2009 y la consolidación de la Fiscalía Especial para los Delitos de Violencia contra las Mujeres y Trata de Personas (FEVIMTRA). Su titular, Sara Irene Herrerías, admitía, en la entrevista que le realizamos en Ciudad de México en julio de 2011, la complejidad de abordar esta problemática ya que "el nexo entre desaparecidas y "guerra del narco" creo puede ser para fines de explotación sexual en el caso de las mujeres, y creo que es por la situación general que hay, cómo se nutren de jóvenes".

La investigación de casos de Secuestro de Mujeres vinculados a redes de Trata con Fines de Explotación Sexual resulta extremadamente compleja por la opacidad existente y el miedo de las propias familias afectadas. Respuestas como "han de estar con los novios, ya volverán" son argumento frecuente de unas Autoridades machistas y negligentes. Las mujeres de Apodaca (Nuevo León) han sufrido en primera personas la implantación de estas redes delictivas en su municipio ante la permisividad más absoluta de las fuerzas policiales y la complicidad de las más altas estancias gubernamentales, entre ellos un alcalde, Benito Caballero, que lejos de mostrar preocupación por las desapariciones de "105 jovencitas en menos de dos años" minimizó los hechos señalando que "cuando visitamos a las familias nos dimos cuenta que no era precisamente que las jóvenes estuvieran secuestradas, sino que agarraron el camino fácil de hacerse pareja sentimental de personas ligadas a la delincuencia”. Pese a la gravedad de unas afirmaciones misóginas que desvelan o un profundo desconocimiento de la forma de actuar de estas estructuras o un afán premeditado de mentir y culpabilizar a las jóvenes secuestradas, el alcalde no recibió la más mínima recriminación ni desde su partido ni desde el Gobierno. Nuevo León se ha consolidado 
como "centro neurálgico de distribución al resto de la República de mujeres para la explotación sexual, negocio que involucra a delincuentes, políticos, funcionarios,

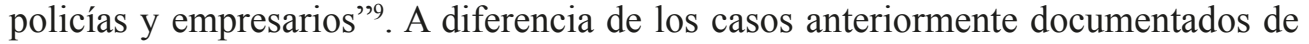
Ciudad Juárez, tras los secuestros sistemáticos de mujeres en Nuevo León sí hay datos concretos sobre los eslabones que actúan como enganches de las jóvenes, entre ellos miembros de Los Zetas.

La trata esconde mucho más que una estructura o un fenómeno coyuntural. La periodista Diana Washington, autora del libro "Cosecha de Mujeres: Safari en el desierto mexicano" y redactora de El Paso Times, investiga desde hace más de una década los casos de desapariciones forzosas y asesinatos de niñas y mujeres en Ciudad Juárez. Washington reconocía en la entrevista realizada en El Paso en julio de 2011 para la elaboración de este trabajo que "la violencia se ha expandido como consecuencia de la "narcoviolencia", que ha utilizado a las mujeres en la redes de crimen organizado, de los pandilleros (...) hay ejércitos de narcotráfico, sicarios, policía corrupta que hace casi imposible investigar (...) con halcones que vigilan y hacen muy arriesgado" realizar un trabajo periodístico. Julia Monárrez, autora de numerosos trabajos e investigaciones relacionadas con la violencia contra las mujeres en Juárez, admitía en la entrevista realizada en enero de 2008 en Juárez que nos enfrentamos a "una cultura del machismo, de menoscabo a las mujeres, una cultura patriarcal institucionalizada, viendo a la mujer desde una óptica de estereotipos sexuales -todo ello en un contexto que- no puede entenderse sin un análisis de la discriminación de género que es histórica (...) y subordinación de la mujer es en todo México".

La expansión y movilidad de las estructuras del crimen organizado también ha conllevado una expansión del fenómeno por diversos estados de la República. Chiapas, situada al sur del país y frontera con Guatemala, se ha convertido en foco central de la Trata de Mujeres y Niñas y eje de actuación del crimen organizado controlado, en gran parte, por Los Zetas. La explotación sexual de niñas y mujeres se ha convertido en algunos Estados en parte de la llamada cultura de los "padrotes" o explotadores de mujeres, extendida en zonas como Tlaxcala. Aquí, se ha consolidado durante décadas "la tradición de ritual masculino que toda la sociedad avala (...) familias enteras viven de la explotación sexual de jovencitas. Los tratantes han sido entrenados para enamorar a adolescentes, establecer noviazgos ficticios, conocer a la familia y llevárselas para prostituirlas" 10 estableciendo todo un sistema que permite que perdure, con toda una infraestructura que dificulta muchísimo la denuncia y desarticulación de estas redes.

Durante la elaboración de este trabajo realizamos seguimientos en zonas "emblemáticas" del Distrito Federal donde los tratantes "exponen" a las víctimas como ganado y comprobamos como son kilómetros enteros de niñas y mujeres "puestas a la venta" con toda una estructura que vigila, que corrompe y que perpetúa el sistema ante los ojos de las propias fuerzas de seguridad. La Merced o el Eje Sullivan son dos de los ejemplos más claros y flagrantes de la complicidad de estas redes con los propios miembros de las fuerzas de seguridad. Ecatepec o Tecámac (en el propio Estado de México) se han convertido también desde 2013 hasta la fecha en focos de 
actuación de estas redes con el secuestro sistemático de más de una decena de adolescentes de entre 14 y 18 años que aún hoy no han sido localizadas.

\section{Colombia: Conflicto armado y crímenes de Estado}

La violencia contra las mujeres como consecuencia de conflictos armados no es "patrimonio" único de México. Esta realidad se ha extendido a muchos países de Centro y Sudamérica como, por ejemplo, Colombia. El trabajo que vienen desarrollando numerosas organizaciones civiles en defensa de los derechos humanos y la denuncia de algunos medios y periodistas de esta realidad ha conseguido comenzar a visibilizar un problema que ha permanecido oculto durante décadas. La violación sistemática de los derechos de las mujeres, agudizada especialmente en algunas zonas del Estado, así como el sistema de impunidad existente durante años para invisibilizar una violencia estructural y sistemática que incluye violaciones, agresiones sexuales, desplazamientos forzosos y asesinatos de miles de niñas y mujeres son algunos de los aspectos abordados en este trabajo.

Hemos de destacar que en 2013 "cada hora cinco mujeres fueron víctimas de violencia" $" 11$ en Colombia, donde en algunos departamentos del Estado se documentó que de forma más aguda "ser mujer es un factor que suscita discriminación, y que, unido al estado de salud, a la edad, a la procedencia religiosa, étnica, cultural y socioeconómica, integra una matriz de factores que sustentan la marginación y la opresión". (Hernández 2010: p449.) El llamado "conflicto armado interno" (Galvis 2009: p11.) colombiano (negado aún hoy por algunos políticos y analistas) ha sustentado las bases de un sistema de hermetismo entorno a la vulneración permanente de los derechos de las mujeres que se prolonga por más de sesenta años y que se ha agudizado en las últimas décadas.

Lo que nació como un movimiento revolucionario contra la opresión en "los enclaves comunistas de autodefensa campesina" (Pizarro 2011: p28.) ha derivado en un complejo entramado ligado al tráfico de drogas y el crimen organizado que bajo el sello de las FARC se ha convertido en brazo opresor y perdido progresivamente apoyo social por sus abusos, el exterminio y el desplazamiento forzoso de miles de campesinos, los mismos a los que desde hace décadas afirman defender. Amnistía Internacional en su informe "Eso es lo que nosotras exigimos. Que se haga justicia: Impunidad por actos de violencia sexual cometidos contra mujeres en el conflicto armado de Colombia" publicado en 2011 denuncia que pese a ello "las FARC continúan teniendo presencia en muchas partes del país (...) las fuerzas de seguridad calculan que las FARC tienen 9.000 combatientes, pero podrían ser el doble si se incluye a los miembros de las milicias".

El avance de estos grupos armados vino acompañado por la comisión de numerosos delitos de género contra mujeres y niñas, desde las amenazas hasta violaciones múltiples. Sin embargo, las fuerzas militares y policiales, lejos de confrontar esta 
realidad, potenciaron el abuso sistemático contra las mujeres campesinas e/o indígenas, al igual que el sistema del terror impuesto por los grupos de paramilitares, que actúan desde hace tiempo con el apoyo de las fuerzas de seguridad, constituidos para hacer frente a la guerrilla insurgente, empleando a las mujeres como "trofeos de guerra". Fuerzas de seguridad, la guerrilla y paramilitares participan por igual en la práctica generalizada y sistemática de violencia sexual en un conflicto donde impera la ley del silencio entre las propias víctimas ante la falta de confianza y seguridad en el propio Estado. "La histórica inexistencia de voluntad política para combatir la impunidad, unas medidas de protección ineficaces para testigos y sobrevivientes, una formación precaria en cuestiones de género para los funcionarios judiciales y la no tipificación en la legislación nacional como crimen de derecho internacional"12 son sólo algunos de los factores denunciados como barreras para conseguir visualizar y confrontar esta realidad escondida y que afecta a miles de mujeres.

La investigadora Paula Guisao afirmaba en el IV Seminario Internacional Políticas de la Memoria celebrado en 2011 en Buenos Aires que la "violencia sexual" se ha convertido en "una práctica generalizada en el conflicto armado colombiano, usada de manera sistemática por todas la partes: guerrilleros, paramilitares y miembros del Ejército y la Policía Nacional; que la utilizan como estrategia de guerra, como forma de tortura o de castigo combinadas con prácticas de mutilación contra mujeres acusadas de simpatizar con el enemigo, como mecanismo para humillar al enemigo o junto a modalidades de esclavitud". El esfuerzo de algunas organizaciones no gubernamentales y la elaboración de trabajos periodísticos dando voz a algunas de las víctimas en los últimos años han logrado destapar, al menos en parte, esta problemática. Pese a ello "la violencia contra las mujeres y las niñas sigue siendo grave, sistemática y generalizada y es utilizada como medios de persecución social y política y arma de guerra por todos los grupos que participan en el conflicto" (Niño 2009: p23.)

A pesar de la gravedad de los hechos aún hoy no existe un registro oficial que recopile datos específicos sobre el número de mujeres y niñas víctimas de violencia sexual en el contexto de un conflicto en el que, como señala la organización ABColombia en su informe "Colombia: Mujeres, Violencia Sexual en el Conflicto y el Proceso de Paz" convergen "factores fuertemente correlacionados entre los intereses económicos y el desplazamiento forzado de las poblaciones, tales como: la minería a gran escala, la agroindustria, y las áreas de importancia estratégica para el tráfico de drogas".

En los últimos 10 años han logrado documentarse numerosos casos de abusos sexuales, secuestros y asesinatos contra niñas y mujeres cometidos por miembros del Ejército Nacional, un hecho aún más grave si cabe al tratarse de representantes que, en teoría, deben ser garantes de la consecución del Estado de Derecho. Esta ausencia de medidas para castigar y perseguir no sólo a los autores de estos delitos, miembros de las Fuerzas de Seguridad, sino a los servidores públicos negligentes, ha propiciado que no exista "un ambiente propicio ni condiciones profesionales de infraestructuras (...) que posibiliten la denuncia de las víctimas. A eso se suman las exigencias del sistema judicial, que piden por ejemplo pruebas materiales de hechos que en muchas 
oportunidades ocurrieron años atrás. (...) las mujeres han señalado que temen que las Autoridades judiciales no crean en sus declaraciones, que sienten que las van a señalar y, que si llegan sin pruebas no tendrán en cuenta sus testimonios" (Guisao, 2011).

Hay que destacar, además, la ausencia durante décadas de políticas encaminadas a avanzar hacia una sociedad más igualitaria; al contrario, el fomento del patriarcado ha arraigado una reacción social. Amnistía Internacional señala en el informe "Eso es lo que nosotras exigimos. Que se haga justicia: Impunidad por actos de violencia sexual cometidos contra mujeres en el conflicto armado de Colombia" que la propia sociedad culpabiliza "a las mujeres y a las niñas en lugar de al autor de los abusos" lo que ha hecho de este fenómeno "un hecho oculto y mayormente silenciado al debate público como un problema de dramáticas dimensiones que desafía a todos los sectores sociales". La propia organización denuncia en el citado trabajo las políticas erráticas del ex Presidente Álvaro Uribe que "enmarcó en reiteradas ocasiones las hostilidades en la "guerra contra el terror", menoscabando así la aplicación del derecho internacional humanitario, que sólo se aplica a situaciones de conflicto armado y permitiendo que los responsables de los ataques contra civiles eludieran la rendición de cuentas".

La visibilización conseguida en los últimos años ha propiciado avances políticos importantes como, por ejemplo, la aprobación de la Ley de Víctimas y Restitución de Tierras impulsada por el Gobierno de José Manuel Santos en 2011, que también "ha reconocido la existencia de un conflicto armado interno" modificando así las políticas precedentes. También a nivel regional o departamental se han logrado avances importantes mediante la planificación de organismos públicos para impulsar políticas igualitarias y proyectos globales desde una perspectiva de género. Un ejemplo de esta apuesta es Medellín (Antioquia) donde en 2007 se creó "la Secretaría de las Mujeres de Medellín (...) con lo cual la capital de Antioquia se convirtió en la primera ciudad colombiana, con una dependencia del más alto nivel administrativo exclusivamente responsable de contribuir a la igualdad de derechos y oportunidades entre mujeres y hombres, tendiente a eliminar las prácticas discriminatorias que por razones de género, obstruyen el desarrollo político, social, económico y cultural de las mujeres del municipio". (Ariza 2011: p80.) Pese a que los resultados de estas iniciativas, a día de hoy, siguen siendo insuficientes, han marcado o pueden marcar el punto de inicio de una nueva etapa y futuros avances en este sentido.

Previa a la citada Ley de Víctimas y Restitución de Tierras, en 2008 la Corte Constitucional de Colombia dictó "una resolución pionera sobre las mujeres desplazadas, el Auto 092, enfocado en el tema de la violencia sexual relacionadas con el conflicto". La ausencia de una base de datos fiable, unido a la minimización permanente de las cifras por parte de las Autoridades son otros de los principales problemas a los que nos enfrentemos a la hora de afrontar esta realidad. Informes elaborados por instituciones prestigiosas u organizaciones no gubernamentales cifran en más de tres millones el número de personas desplazas por el conflicto armados en las últimas dos décadas, siendo las mujeres y las niñas el colectivo más damnificado, sufriendo una triple persecución y discriminación por su condición de: mujeres, pobres y desplaza- 
das. Zonas como Arauca, el Valle del Cauca, Chocó o Meta han sido señaladas como focos rojos de violencia contra las mujeres por parte de guerrilleros, paramilitares y fuerzas de seguridad.

Nos enfrentamos en muchos de los casos a crímenes de Estado que, contrario a lo que parece haberse difundido y consolidado entre la opinión pública colombiana, no se remontan a décadas pasadas, sino que han seguido ocurriendo en el pasado reciente con el Gobierno liderado por Álvaro Uribe. El que fuera Presidente colombiano entre 2002 y 2010 está en el "punto de mira de la Corte Penal Internacional (...) por crímenes contra los Derechos Humanos y masacres sucedidas durante su mandato, que no han sido tratados a fondo por la justicia colombiana (...) asesinatos cometidos para aumentar los índices de éxito militar que podrían considerarse crímenes de lesa humanidad"13.

Otro de los problemas fundamentales que dificultan la erradicación de esta situación es la ausencia de información y la escasez de tratamiento periodístico de esta problemática por parte de los principales medios de comunicación en Colombia. Mientras que en México han proliferado numerosos medios independientes en las redes que han ejercido un importantísimo papel de contrainformación o información alternativa, en Colombia el fenómeno sigue sin consolidarse entre la población.

\section{Conclusiones}

El periodismo se ha convertido en una de las principales fuentes para combatir esta impunidad gracias a los trabajos y las investigaciones que han conseguido visibilizar aspectos hasta no hace tantos años acallados como el propio Estado, parte directa del problema y actor principal de los capítulos estudiados. Junto a los medios, el papel de las organizaciones civiles, y de las propias familias afectadas, han sido también motores fundamentales para dar a conocer una realidad tan compleja y peligrosa que, además, esconde toda una cadena de intereses y complicidades asentados en un sistema patriarcal y misógino que potencia su pervivencia.

El conocimiento es una pieza fundamental para la educación de una nueva sociedad y "puede tener un papel conformador y transformador de conciencias y que, desarrollar desde la primera infancia, debe fomentar actitudes igualitarias, tolerantes y respetuosas para con el otro" (Amenábar 2013: p127.) Centrándonos en el caso de México, hemos de poner en valor la valentía de algunos periodistas que, pese a las amenazas y las adversidades, decidieron afrontar investigaciones plagadas de escollos y aristas extremadamente peligrosas debido a la implicación directa de actores con poder tras los capítulos analizados. "México es uno de los países más peligrosos del mundo para los periodistas; las amenazas y los asesinatos a manos del crimen organizado -incluso de las autoridades corruptas- son cosa de todos los días"14, según Reporteros Sin Fronteras, asociación que en la última década ha documentado los asesinatos de más 80 periodistas en suelo mexicano y la desaparición de otros 17. 
En su Informe Anual de 2013, la Asociación Artículo 19 concluyó que “cada 26 horas y media fue agredido un periodista en México" a lo largo del citado año, figurando Chihuahua y Tamaulipas (Estados de los que hemos hablado en este artículo) entre los cuatro Estados con mayores índices de denuncias por agresiones a reporteros.

La práctica periodística en México en general, y en Ciudad Juárez y la zona del golfo en particular, se ha convertido en una profesión de alto riesgo. Durante la elaboración de este artículo hemos podido constatar cómo algunos reporteros en Juárez deben aprender primeros auxilios ante la posibilidad de sufrir un atentado. La mencionada Asociación Artículo 19 ha editado incluso manuales dirigidos a los reporteros aconsejándoles cómo actuar ante amenazas, atentados o secuestros (Artículo 19 2010: p79.) ya que, lamentablemente, estos fenómenos se han convertido en parte de la profesión periodística en México. Pese a todas estas trabas, el trabajo de algunos medios y periodistas ha conseguido visibilizar aspectos como las negligencias que aún hoy se cometen por parte de las Autoridades a la hora de investigar los casos de feminicidios sistemáticos de mujeres y niñas en Ciudad Juárez, o al enfrentarse a las estructuras del crimen organizado que se esconden tras las herméticas redes de trata de mujeres con fines de explotación sexual que se expanden por toda la República. Ciñéndonos al caso de Ciudad Juárez, resulta enormemente llamativo la desinformación existente entre la ciudadanía sobre los capítulos de desapariciones sistemáticas de niñas y mujeres y los feminicidios sexuales documentados desde hace ya más de 20 años.

Durante la elaboración de este trabajo en la ciudad fronteriza pudimos verificar la falta de información entre la propia población juarense en general y entre los más jóvenes en particular. A pesar de la gravedad de los hechos documentados a lo largo de décadas, hay un preocupante desconocimiento entre la población debido, por un lado, al desinterés de la propia Autoridad y, por otro, al papel "permisivo" de algunos medios influyentes que lejos de adoptar una postura crítica y de denuncia contra una Autoridad culpable, que incluso fue condenada por negligencias de Estado por la Corte Interamericana de Derechos Humanos en 2009 por su labor deficiente a la hora de investigar los homicidios de ocho jovencitas localizadas asesinadas en un "Campo Algodonero" de Juárez en noviembre de 2001, ha preferido desde hace años dar cobertura a las "excusas" y versiones oficiales, con lo que "avalan la irregular actuación de las autoridades en esta historia" (Pérez 2012: p120.) y arremeter, incluso, contra activistas por, supuestamente, hacer de Ciudad Juárez una "víctima de una leyenda negra" (Diario de Juárez,05-06-06) injustificada y por su supuesto lucro, una realidad denunciada por periodistas como Judith Torrea que señala además como a una determinada activista "se la intentó desprestigiar en su propia tierra con campañas mediáticas (...) para acallarla desde el mayor periódico del Estado, El Diario de Juárez, del que es accionista" (Torrea 2011: p45.) el ex Gobernador Patricio Martínez. La activista Marisela Ortiz denunció, en la entrevista realizada en 2008 para la elaboración de este trabajo, la existencia de "un Plan del Gobierno del Estado, firmado por empresarios, medios y universidad para limpiar la imagen de la ciudad a costa de ocultar información, negar la información a la que tenemos derechos; con 
programas donde nos ponen como delincuentes, nos acusan de lucro, de traicionar a la patria con promociones para unirse contra nosotras porque desprestigiamos a la Comunidad, porque exageramos, dicen, los datos y eso, asegura, aleja la inversión". Marisela y su familia viven en la actualidad exiliados en Estados Unidos tras ser amenazados de muerte.

El auge de las redes sociales y la proliferación de numerosos medios digitales "independientes" en México y Colombia ha impulsado el flujo de información y favorecido la visibilización de denuncias civiles y problemáticas acalladas. Sin embargo, la opacidad informativa se ha convertido en uno de los principales escollos a la hora de abordar casos como los anteriormente expuestos, también en Colombia, donde, pese a lo avances logrados en materia de seguridad, el periodismo supone una profesión de alto riesgo. En la actualidad hay en la República "93 periodistas amenazados (...) de estos casos, cincuenta y seis han sido catalogados como extraordinarios y 37 como ordinario" 15 siendo Bogotá, Valle del Cauca, Antioquia y Arauca los espacios más conflictivos para la práctica informativa.

Es cierto que para lograr avanzar en la erradicación de la violencia contra las mujeres en Colombia es necesaria una mayor visibilización de la dimensión del problema como paso previo a una concienciación social que, aún hoy, es muy insuficiente. Durante la elaboración de este artículo también hemos visitado Colombia y hemos podido constatar el profundo desconocimiento de la población civil de las atrocidades cometidas por el propio Estado contra mujeres y niñas en espacios donde afectados por el conflicto armado. Al igual que en México, las organizaciones no gubernamentales defensoras de los derechos humanos han sido, en Colombia, objeto de acoso y están en el punto de mira de los actores implicados en las situaciones descritas en este trabajo y continúan las amenazas y los homicidios.

Tanto en México como en Colombia la impunidad es un lastre que impide avanzar para "buscar la raíz del problema en el universo cultural de la sociedad patriarcal" (Marugán 2012: p158.) Aún hoy es muy complejo, por no decir imposible, dar seguimiento a las denuncias, lo que ha provocado, en cierto grado, el desánimo de los propios reporteros que han ahondado en sus investigaciones y que han aportado infinidad de pruebas demostrando negligencias y participación directa de funcionarios e altos cargos políticos. Este es el caso de la periodista Lydia Cacho, que incluso aportó conversaciones telefónicas entre el empresario Kamel Nacif y el Gobernador de Puebla Mario Marín (PRI) donde se documentaba la implicación de ambos en una red de prostitución de menores y que "muestran (...) como el poder del dinero y el poder político se entrelazan para protegerse (...) y los enlaces de estas redes de poder" (Cacho 2008: p14.) Pese a ello, Cacho fue la única juzgada y perseguida por la denuncia, sufriendo posteriormente una intensa campaña de acoso y amenazas.

Por último, debemos destacar la importancia de la educación como única garantía de cambio. En los últimos años, algunas Universidades, tanto en México como en Colombia, han implementado programas y/o departamentos específicos para impulsar la formación del alumnado desde una perspectiva de género, lo que supone, sin 
duda, un gran avance. Sólo la educación podrá revertir esta realidad e imponerse al silencio y la impunidad presente. La educación es la única bala cargada de futuro.

\section{Referencias bibliográficas}

AMENÁBAR, José Martín (2013). "Miedos masculinos y mutilación genital femenina”. En Raudem, Revista de Estudios de las Mujeres. Volumen I. Universidad de Almería. Pp. 110-130.

ARIZA SOSA, Gladys Rocío (2011). "Hacia la definición de la violencia en las relaciones de pareja como un problema de salud pública en Medellín a comienzos del siglo XXI”. En: Feminismo /s: revista del Centro de Estudios sobre la Mujer de la Universidad de Alicante, Número 18, Alicante. Pp. 67-92.

CACHO, Lydia. "Memorias de una infamia". Debate. Barcelona. 2008.

CHÁVEZ DÍAZ, Miguel Ángel (2009) en PÁEZ VARELA, Alejandro (Coordinador). 2009. "La guerra en Juárez". México DF: Temas de Hoy

FEMENÍAS, María Luisa (2010) en López Fernández, M.; Posada Kubissa, L. (Coords). "Pensar con Celia Amorós". Madrid: Editorial Fundamentos.

FLÓREZ, Margareth. "Construcción de Capital Social y Organizaciones Comunitarias en Bogotá". Fundación Coronas. Colombia. 2005

GALVIS, María Clara. "Situación en Colombia de la Violencia sexual contra las mujeres". Ediciones Átropos. Bogotá. 2009.

GONZÁlEZ RODRÍGUEZ, Sergio. "Huesos en el desierto". Anagrama. Barcelona. 2002.

HERNÁNDEZ, Colombia; YESPES, Fanny Lucía (2010) "Haciendo visible lo invisible. Violencia de género y entre generaciones en una comunidad indígena colombiana". En: Revista Investigación y Educación en Enfermería, volumen 28, número 3. pp. 444-453. Universidad de Antioquia. Medellín. Colombia.

JUÁREZ RODRÍGUEZ, Javier. “Desaparecidas en Ciudad Juárez”. Amargord. Madrid. 2012.

LAGARDE DE LOS RÍOS, Marcela. "El feminismo en mi vida: Hitos, claves y topías". Inmujeres. México. 2012.

LIMAS, Alfredo; RAVELO, Patricia. "Feminicidio en Ciudad Juárez: una civilización sacrificial”. El Cotidiano, vol. 18, núm. 111, enero-febrero, 2002. Universidad Autónoma Metropolitana Azcapotzalco. México.

MARUGÁN PINTOS, Begoña (2012) "Domesticar la violencia contra las mujeres, una forma de desactivar el conflicto intergéneros". En: Investigaciones Feministas. Volumen 3. Universidad Complutense de Madrid. España. Pp. 155-166.

MEJÍA QUINTANA, Óscar (Director). "Democracia y medios de comunicación en Colombia”. Universidad Nacional de Colombia. Bogotá. 2011.

MOLINA, Estefanía; SAN MIGUEL, Nava (Coords). "Universidad, Género y Desarrollo. Nuevas líneas de Investigación en Género y Desarrollo". UAM Ediciones. Madrid. 2009. 
NIÑO, Lucy; NÚÑEZ Lida. "Colombia: violencia contra las mujeres y las tecnologías de información y comunicación. ¿Superando el patriarcado?”. Asociación para el Progreso de las Comunicación. Octubre 2009.

PÉREZ, Rosa Isela (2012) en BERNABÉU ALBERT, Salvador; MENA GARCÍA Carmen (Coords) "El feminicidio de Ciudad Juárez. Repercusiones legales y culturales de la impunidad". Sevilla: Universidad Internacional de Andalucía.

PIZARRO LEONGÓMEZ, Eduardo. "Las FARC (1949-2011) De guerrilla a máquina de guerra”. Grupo Editorial Norma. Bogotá. 2011.

PLASENCIA VILLANUEVA, Raúl. "La Comisión Nacional de Derechos Humanos, los homicidios y las desapariciones de mujeres en Ciudad Juárez (1993 2009)”. Comisión Nacional de Derechos Humanos. México DF. 2009.

TAJAHUERCE, Isabel (Coordinadora). "Mujeres y Comunicación". La Linterna Sorda. Madrid. 2014.

TORREA, Judith. "Juárez en la sombra: Crónicas de una ciudad que se resiste a morir”. Aguilar. Madrid. 2011.

VARELA, Nuria. "Feminismo para principiantes". Ediciones B. Barcelona 2005.

WASHINGTON VALDEZ, Diana. "Cosecha de Mujeres. Safari en el desierto mexicano". Océano. Barcelona. 2005.

Otros documentos:

ABColombia. "Colombia: Mujeres, Violencia Sexual en el Conflicto y el Proceso de Paz". Londres. Noviembre 2009. Página 9.

Amnistía Internacional. "Eso es lo que exigimos. Que se haga Justicia. Impunidad por actos de violencia sexual cometidos contra mujeres en el conflicto armado de Colombia". Londres. Septiembre 2011. Página 10.

Asociación Artículo 19. "Prevenir para después informar: Guía práctica de seguridad para la cobertura de zonas de riesgo". México. 2010.

BENGOECHEA, Mercedes y Ma Luisa CALERO. "Sexismo y redacción periodística". Junta de Castilla y León. Valladolid. 2003

Centro de Derechos Humanos de las Mujeres AC y Justicia Para Nuestras Hijas AC. "Información para el pacto de derechos politicos y sociales sobre feminicidio y desapariciones en Ciudad Juárez y Chihuahua y sobre violaciones a derechos humanos de las mujeres en el contexto de militarización y narco-violencia". Ciudad Juárez. 2010.

Fiscalía Especial para Delitos de Violencia contra las Mujeres y Trata de Personas. "Informe Especial". México. 2011.

GILETTI BENSO, Silvia. “Los crímenes de género y sus huellas: Aproximación al femigenocidio". Revista Telemática Di Estudi Sulla Memoria Femminile. 2014.

GUISAO LÓPEZ, Paula (2011). "De mujeres, luchas y memorias en el conflicto colombiano" en IV Seminario Internacional Políticas de la Memoria. Buenos Aires.

LIMAS HERNÁNDEZ, Myrna. "Desarrollo Humano desde la perspectiva de género: El caso de las mujeres en Ciudad Juárez, México". Universidad Autónoma de Madrid. 2011. 
LÓPEZ FLORES, Raúl (Director). 2010. "Estudios sobre la Trata de Personas en México". Instituto Belisario Domínguez del Senado de la República de México. Dirección General de Estudios Legislativos: Investigaciones Sociales. México.

MONÁRREZ FRAGOSO, Julia Estela. "Peritaje sobre feminicidio sistemático en Ciudad Juárez: Caso 12.498 González y otras vs México. Campo Algodonero". 2009.

PADILLA, Héctor, PÉREZ ESTELA, Martha. 2002. "Interpretaciones Locales sobre la violencia en contra de las mujeres en Ciudad Juárez". Revista de Estudios de Género La Ventana, Número 15. Página 223

RAVELO, Patricia. "El fenómeno del feminicidio: Una propuesta de recategorización". Centro de Investigaciones y Estudios Superiores en Antropología Social (CIESAS). 2006.

Diarios Impresos:

Diario de Juárez, 05-06-06

Diario de Juárez, 23-01-2008

Diario de Juárez, 14-04-2011

Diario de Juárez, 17-04-2012

Norte de Ciudad Juárez, 26-02-1012

Norte de Ciudad Juárez, 24-07-11

\section{Notas}

1 http://www.jornada.unam.mx/2011/04/14/politica/011n2pol

2 http://contralinea.info/archivo-revista/index.php/2014/03/25/en-mexico-una-mujer-asesinada-cada-3-3-horas/alcanzado

$3 \mathrm{http}: / /$ www.elespectador.com/noticias/actualidad/mujeres-mexicanas-botin-de-guerra-un-pais-donde-prevale-articulo-456379

4 http://www.sinembargo.mx/21-10-2013/788369

5 http://www.excelsior.com.mx/node/720467

6 http://www.sinembargo.mx/14-03-2012/181392

7 http://laopcion.com.mx/noticia/24515

$8 \mathrm{http} / /$ www.zocalo.com.mx/seccion/articulo/a-la-caza-de-mujeres-desaparecidos-de-la-narcoguerra

9 http://www.jornada.unam.mx/2011/08/14/politica/002n1pol

$10 \mathrm{http}: / /$ www.eluniversal.com.mx/columnas/86611.html

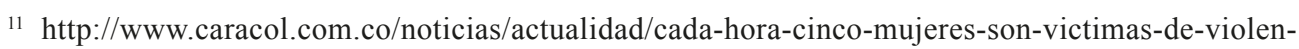
cia-en-colombia/20131125/nota/2023794.aspx

$12 \mathrm{http} / /$ www.semana.com/nacion/articulo/en-colombia-mujeres-ninas-menudo-tratadas-como-trofeos-guerra/246728-3 
${ }^{13} \mathrm{http} / /$ www.publico.es/internacional/450217/uribe-en-el-punto-de-mira-de-la-corte-penal-internacional-por-las-masacres-durante-su-mandato

${ }^{14} \mathrm{http} / / / \mathrm{es} . r s f . o r g /$ report-mexico, $184 . \mathrm{html}$

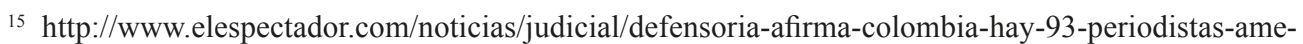
nazado-articulo-510619

\section{El autor}

Javier Juárez Rodríguez (Madrid, 1978) Licenciado en Periodismo por la UEM. DEA en periodismo por la UEM. Doctorando en la Unidad de Igualdad de la Universidad Complutense de Madrid. Especializado en periodismo de investigación desde una perspectiva de género. Autor del libro "Desaparecidas en Ciudad Juárez" (Amargord, 2012) Ha publicado trabajos de investigación en medios de México, España y Estado Unidos. Ha impartido cursos y seminarios en universidades de España y Colombia. 